\title{
Depressive Symptoms in Pregnancy: The Influence of Social, Psychological and Obstetric Aspects
}

\section{Sintomas depressivos na gestação: influência dos aspectos social, comportamental, psicológico e obstétrico}

\author{
Eleomar Vilela de Moraes ${ }^{1}$ Rodolfo Nunes Campos ${ }^{2}$ Mariza Martins Avelino ${ }^{3}$
}

${ }^{1}$ Faculdade de Medicina, Universidade Federal de Goiás (UFG), Goiânia, Goiás, Brazil

Address for correspondence Ms. Eleomar Vilela de Moraes, MSc, Universidade Federal de Goiás (UFG), 1av. s/n - S. Universitário, 74605-

2 Departament of Mental Health and Forensic Medicine, Faculdade de 020, Goiânia - Goiás, Brazil (e-mail: veleomar@gmail.com).

Medicina, Universidade Federal de Goiás (UFG), Goiânia, Goiás,

Brazil

3 Departament of Pediatrics and Puericulture, Faculdade de Medicina,

Universidade Federal de Goiás, Goiânia, Goiás, Brazil

Rev Bras Ginecol Obstet 2016;38:293-300.

\begin{abstract}
Keywords

- prenatal depression

- pregnancy

- prevalence

- cross-sectional studies

- public health

Purpose To assess the prevalence of depressive symptoms and their association with social, psychological, behavioral and obstetric characteristics in pregnant women.

Methods This is a cross-sectional study. The sample consisted of 375 pregnant women who attended prenatal clinics in two public maternity hospitals located in the city of Goiania, Brazil. To testify the depressive symptoms, we used the Hospital Anxiety and Depression Scale (HADS). A descriptive statistical analysis was performed using programs such as CDC EPI-INFO'M, version 7.1.5, and Statistical Package for Social Sciences (IBM SPSS), version 21.0.

Results the patients had probable depressive symptoms (15.47\%) and possible depressive symptoms (25.33\%). The bivariate analysis showed a significant association among "depressive symptoms" and the following variables: "single or divorced" (prevalence ratio, $\mathrm{PR}=2.08$; $95 \%$ confidence interval, $\mathrm{Cl}=1.26$ to 3.44 ); "physical activity during pregnancy" ( $P R=3.96 ; 95 \% \mathrm{Cl}=1.28$ to 12.31 ); exposure to "psychological/emotional" violence ( $\mathrm{PR}=4.74 ; 95 \% \mathrm{Cl}=2.94$ to 7.64 ); "prior mental problem" ( $P R=2.66 ; 95 \% \mathrm{Cl}=1.49$ to 4.73$)$ and "obstetric complications during pregnancy" ( $P R=2.53 ; 95 \% \mathrm{Cl}=1.55$ to 4.13$)$. The multivariate analysis confirmed the association of these depressive symptoms with the variables "suffered psychological/emotional violence" (odds ratio, $\mathrm{OR}=5.821 ; 95 \% \mathrm{Cl}=2.939$ to 11.528 ); "physical activity during pregnancy" ( $\mathrm{OR}=3.885 ; 95 \% \mathrm{Cl}=1.060$ to 14.231$)$; "obstetric complications during pregnancy" $(\mathrm{OR}=2.442 ; 95 \% \mathrm{Cl}=1.233$ to 4.834$)$ and "single or divorced" $(\mathrm{OR}=2.943 ; 95 \% \mathrm{Cl}=1.326$ to 6.533$)$.
\end{abstract}

received January 17, 2016 accepted May 19, 2016
DOI http://dx.doi.org/ 10.1055/s-0036-1585072. ISSN 0100-7203.
Copyright ( $\odot 2016$ by Thieme Publicações License terms Ltda, Rio de Janeiro, Brazil

() (1) $\odot \circledast$ 


\section{Resumo}

\author{
Palavras-chave \\ - depressão pré-natal \\ - gravidez \\ - prevalência \\ - estudos transversais \\ - saúde pública
}

Conclusions the prevalence of depressive symptoms among pregnant women is of $15.47 \%$, and emotional violence is the main factor associated with gestational depression.

Objetivo verificar a prevalência de sintomas depressivos e suas associações com características sociais, psicológicas, comportamentais e obstétricas em mulheres grávidas.

Métodos trata-se de estudo transversal. A amostra constou de 375 grávidas atendidas no ambulatório de pré-natal de duas maternidades públicas localizadas na cidade de Goiânia. Para a comprovação dos sintomas depressivos, empregou-se a Hospital Anxiety and Depression Scale (HADS). Foi realizada análise estatística descritiva com auxílio dos programas CDC EPI-INFO'TM, versão 7.1.5, e Statistical Package for Social Sciences (IBM SPSS), versão 21.0.

Resultados apresentaram prováveis sintomas depressivos e possíveis sintomas depressivos $15,47 \%$ e $25,33 \%$ das entrevistadas, respectivamente. A análise bivariada demonstrou associação significante entre "sintomas depressivos" e as seguintes variáveis: "solteira ou separada" (razão de prevalência, RP $=2,08$; intervalo de confiança, IC95\% = 1,26-3,44); "atividade física na gestação" (RP = 3,96; IC95\% $=1,28-12,31)$; submissão a "violência psicológica/emocional" $(R P=4,74 ;$ IC95\% = 2,94-7,64); "problema mental prévio" ( $R P=2,66$; IC95\% = 1,49-4,73) e "complicações obstétricas na gestação atual” ( $R P=2,53$; IC95\% $=1,55-4,13)$. A análise multivariada confirmou associação desses sintomas depressivos com as variáveis "sofreu violência psicológica/emocional" (odds ratio, OR =5,821; IC95\% =2,93911,528); “atividade física na gestação" (OR = 3,885; IC95\% =1,060-14,231); “complicações obstétricas na gestação atual" (OR=2,442; IC95\%=1,233-4,834); e "solteira ou separada" (OR = 2,943; IC95\% = 1,326-6,533).

Conclusões a prevalência de sintomas depressivos entre as grávidas é de 15,47\%, e a violência emocional é o principal fator associado à depressão gestacional.

\section{Introduction}

International studies have shown that the prevalence of depression in pregnancy can vary from $8.6 \%$ in the Middle East, $19.5 \%$ in Western Europe, ${ }^{1}$ and $33 \%$ in the United States. ${ }^{2}$ In Brazil, studies on the subject are scarce, and the prevalence can range from $15^{3}$ to $28 \%{ }^{4}$ Risk factors for gestational depression are mostly linked to indicators of socioeconomic deprivation, such as unemployment, financial hardship and low education. Moreover, having a history of violence, stressful episodes, psychiatric history, being single or divorced ${ }^{3}$ and the lack of social support ${ }^{5}$ were also associated with gestational depression.

Depression during prenatal care is a pathological episode; although not studied extensively, ${ }^{6}$ it can be a predictor of postpartum depression and clinical implications such as depression, a high risk of premature birth, low birth weight and surgical birth. ${ }^{7}$ In addition, a recent cohort study, which included 2,072 pregnant women, also found a relationship between depression in pregnancy and the early termination of breast-feeding. ${ }^{8}$

The psychological condition of the mother during pregnancy is different, a result of complex endocrine variations. It is important to mention that, in an experimental study using a prenatal stress model in female rats that developed trauma early in pregnancy, it was found that early environmental health problems, such as repeated maternal stress, could produce lasting changes in the function of neural circuits in the offspring. ${ }^{9}$ These neurobiological changes will have implications for several psychiatric conditions, including abuse and dependence of psychoactive substances. ${ }^{10}$ In humans, stressful events like these may have consequences for the mother in the form of depression and, at a worst assumption, they can lead to suicide. ${ }^{11}$

Depression is the result of a sophisticated interplay of social, psychological and biological factors. In this context, social circumstances such as economic pressures, unemployment and family dispute may increase the risk of disease. Considered difficult to treat, depression can cause psychic suffering. ${ }^{12}$ That suffering includes the impairment of quality of life, relationships and activities due to the patient's functional disability, which leads to the emergence of disorders that are more serious, and to the increase in demand for public health services. ${ }^{13}$

On the other hand, social support can mitigate depressive episodes, particularly in the presence of physiological and psychosocial changes, such as in pregnancy. ${ }^{5}$ In addition, teaching positive confrontation can minimize the manifestation of these events. ${ }^{14}$ 
As evidenced in the literature, performing physical activity during pregnancy can also reduce instances of depression, causing well-being and preventing weight gain, urinary loss and diabetes. ${ }^{15}$ A study conducted in England to determine the effectiveness of exercise during pregnancy has detected an increase in the number of normal deliveries directly proportional to the frequency of physical activity. ${ }^{16}$

Despite the existence of known and effective therapies, less than half of the population affected globally receives treatment. Barriers to care include the social stigma related to mental disorders and the lack of resources and trained health care professionals. ${ }^{11}$

Considering the seriousness of the issue and the literature shortage, identifying the occurrence of mental disorders may contribute to an improvement in planning primary attention. ${ }^{13}$ As the Women's Health Program adopted in Brazil direct assistance to women's health for reproductive purposes, the occasion becomes timely for interventions that empower pregnant women, their families and society. ${ }^{17}$

Given the facts, this study aimed to determine the prevalence of depressive symptoms and their association with social, psychological, behavioral and obstetric aspects in pregnant women admitted to two public hospitals in the city of Goiânia.

\section{Methods}

This is a descriptive cross-sectional study. The study involved pregnant women of low and high risk enrolled in prenatal clinics at two Public Maternity Hospitals of reference in the city of Goiânia, Brazil. These institutions perform care assistances, research and teaching, and serve the local community and several regions of the state. Data were collected from September 2014 to May 2015.

The sample consisted of pregnant women aged over 18 years. Half of the pregnant women present were invited to participate, representing the even numbers by scheduling order.

To calculate the size of the sample, it has been taken the total of 4,826 prenatal attendances in the two maternity hospitals during the collection period, an estimated proportion of $28.3 \%$ depression in pregnancy, ${ }^{4}$ a type I error of $5 \%$ and $95 \%$ confidence interval. The minimum universe obtained was 292 pregnant women, but, set to final sample size of 375 pregnant women anticipating possible unanswered questions. $^{18}$

In order to collect the data, we used a self-administered instrument, with the inclusion of additional information in the form of bold explanatory notes, to facilitate the application, the filling and the typing of said instrument.

The instrument with data on social and economic profiles presented questions containing age, education, marital status and economic situation. Low education was set as having eight years of schooling or less; average education was set as having nine to eleven years of schooling; and high education was set as having twelve years of schooling or more. Regarding the economic situation, we considered of low income those households with a monthly income of up to three minimum wages. ${ }^{19}$
Through suggested questions posed by the authors, we investigated several stressful events experienced by pregnant women, such as episodes of physical and emotional/ psychological violence, obstetric complications in the current pregnancy, and the previous psychiatric history of the pregnant women and their families.

The pilot was previously applied to fifteen pregnant women. The aim was to: detect possible errors in the investigation; detect ambiguities in the questions made by the authors of this study; and comprehend the difficulties. After realizing the errors, the necessary corrections were performed.

To detect depressive symptoms during pregnancy, we used the Hospital Anxiety and Depression Scale (HADS) of Zigmond and Snaith, ${ }^{20}$ validated in Brazil for outpatients. ${ }^{21}$ This scale can be applied in multiple contexts, ${ }^{22}$ such as in maternity and pre-natal services. ${ }^{3}$

This scale consists of fourteen items that mention the emotional state and do not address somatic symptoms indicating therefore greater chance of diagnose depression. Of these, seven are related to anxiety (HADS-A), and the other half, to depression (HADS-D), with cutoff points from seven to eight for anxiety and depression respectively. For Botega et $\mathrm{al}^{21}$ the cutoff point that provided good sensitivity and good specificity was $7 / 8$ (that is, from 8 points) in the subscale of depression (85\% and $72.4 \%$ respectively).

Each question has four alternatives with a score, which ranges from zero to three, and the sum of the points can vary from zero to 21 for each disorder. The higher the score, the greater the chance for minor mental disorders (MMD).

According to the results achieved in each subscale, the patient was placed on three levels: the unlikely event (zero to seven points); the possible/doubtful event (eight to ten points); and the probable case (eleven to twenty one points). ${ }^{20}$

To know the reliability of the instrument (the HADS), we made the calculation of Cronbach's $\alpha$, considering that the higher the coefficient, the more reliable the instrument. ${ }^{23}$ Thus, the value above 0.70 was adopted as suitable for this research. $^{24}$

We excluded illiterate pregnant women who did not agree to complete the questionnaire, who did not answer all the questions of the HADS, who lived out of state, or who had a previous diagnosis of neurological diseases, such as multiple sclerosis and movement disorders.

We analyzed the data with the help of CDC EPI-INFO ${ }^{\mathrm{TM}}$, version 7.1.5, and the Statistical Package for Social Sciences (IBM SPSS), version 21.0. For the descriptive analysis of the quantitative variables, we used measures of central tendency (mean and median), dispersion measures (standard deviation, SD) and simple and absolute frequencies for ordinal variables. To verify the associations between variables and depressive symptoms, a bivariate analysis using the Chisquare $\left(\chi^{2}\right)$ test, Fisher's Exact and prevalence ratio (PR) was performed. To estimate the PR, we chose to perform a logistic regression analysis, justified by the low outcome of dependent variable. ${ }^{25}$ The entrance was the hierarchical type, and the explanatory variables were based on the 
Table 1 Socioeconomic characteristics and their association with the depressive symptoms of pregnant women assisted in two public hospitals of reference in the city of Goiânia, Brazil, 2015 ( $n=375)$

\begin{tabular}{|c|c|c|c|c|c|c|}
\hline \multirow[t]{3}{*}{ Characteristics } & \multicolumn{4}{|c|}{ Depressive Symptoms $^{* *}$} & \multirow{2}{*}{\multicolumn{2}{|c|}{ Statistics }} \\
\hline & \multicolumn{2}{|l|}{ Yes } & \multicolumn{2}{|l|}{ No } & & \\
\hline & $\mathrm{n}$ & $\%$ & $\mathrm{n}$ & $\%$ & PR $(95 \% \mathrm{Cl})$ & $P$ \\
\hline \multicolumn{7}{|l|}{ Age Group ${ }^{* * *}$} \\
\hline 19 to 26 & $30 / 212$ & 14.15 & $182 / 212$ & 85.85 & $0.83(0.52-1.34)$ & $0.454^{*}$ \\
\hline 27 to 55 & $27 / 159$ & 16.98 & $132 / 159$ & 83.02 & & \\
\hline \multicolumn{7}{|l|}{ Single/divorced } \\
\hline Yes & $16 / 58$ & 27.59 & $42 / 58$ & 72.41 & $2.08(1.26-3.44)$ & $0.005^{*}$ \\
\hline No & $42 / 317$ & 13.25 & $275 / 317$ & 86.75 & & \\
\hline \multicolumn{7}{|l|}{ Years of education ${ }^{* * *}$} \\
\hline$\leq 8$ years of education & $18 / 85$ & 21.18 & $67 / 85$ & 78.82 & $1.55(0.93-2.58)$ & $0.090^{*}$ \\
\hline$>8$ years of education & $38 / 279$ & 13.62 & $241 / 279$ & 86.38 & & \\
\hline \multicolumn{7}{|l|}{ Family income ${ }^{* * *}$} \\
\hline$\leq$ three minimum wages ${ }^{* * * *}$ & $41 / 272$ & 15.07 & $231 / 272$ & 84.93 & $0.70(0.33-1.51)$ & $0.379^{*}$ \\
\hline$>$ three minimum wages ${ }^{* * * *}$ & $6 / 28$ & 21.43 & $22 / 28$ & 78.57 & & \\
\hline \multicolumn{7}{|l|}{ Religious ${ }^{* * *}$} \\
\hline No & $9 / 48$ & 18.75 & $39 / 48$ & 81.25 & $1.23(0.65-2.34)$ & $0.533^{*}$ \\
\hline Yes & $48 / 315$ & 15.24 & $267 / 315$ & 84.76 & & \\
\hline
\end{tabular}

Abbreviations: $\mathrm{Cl}$, confidence interval; $\mathrm{n}$, number; $\mathrm{PR}$, prevalence ratio.

${ }^{*}$ Chi-square test; ${ }^{* *}$ Punctuation $\geq 12$ in the subscale of depression of the Hospital Anxiety and Depression Scale (HADS); ${ }^{* * *}$ Some did not respond; ${ }^{* * * *}$ Minimum wage $=R \$ 788.00$ (roughly US\$262.00 in 2015).

borderline $p$-value $(p \leq 0.010)$ and the clinical importance. ${ }^{26}$ For all tests, it was considered statistically significant a $p$ value less than or equal to $5 \%(p \leq 0.05)$ at the $95 \%$ CI. The variable "depressive symptoms" in prenatal care was defined as a dependent.

The study was approved by the Research Ethics Committee at Universidade Federal de Goiás (case No. 786.358). The provisions of Resolution No. 466/12, from the Brazilian National Council for Health, were respected.

\section{Results}

All 375 pregnant women were aged between 19 and 55 years old $(27.06 \pm 6.63)$, had average gestational age of $27 \pm 10.60$ weeks, and low-risk pregnancies (56.52\%).
Most were married or lived with a partner (84.53\%), had more than eight years of schooling (76.42\%), were unemployed (55.95\%), but had an employed partner (91.14\%). Most families had an income lower or equal to three minimum wages (90.67\%). We also found that $87.00 \%$ followed a religion, and of these, $44.53 \%$ identified themselves as Evangelical.

In - Table 1, the bivariate analysis showed a statistically significant association between "depressive symptoms" and being "single/separated."

One in four pregnant women was found to present "possible or doubtful" depressive symptoms. With respect to the internal consistency of the items for the subscale ADH, Cronbach's alpha of 0.73 allows reliability of the measurements ( - Table 2).

Table 2 Description of depressive symptom prevalence detected by the Hospital Anxiety and Depression Scale applied to pregnant women admitted to two public hospitals of reference in the city of Goiânia, Brazil, $2015(n=375)$

\begin{tabular}{|c|c|c|c|c|c|}
\hline HAD-D Subscales* (7 items) & n (\%) & CA & Obt int & Median & Average $(\mathrm{SD})^{* *}$ \\
\hline & & 0.73 & $0-18$ & 7 & $6.87(4.03)$ \\
\hline Improbable (0-7 points) & $222(59.20)$ & & & & \\
\hline Possible/doubtful (8-11 points) & $95(25.33)$ & & & & \\
\hline Probable (12-21 points) & $58(15.47)$ & & & & \\
\hline
\end{tabular}

Abbreviations: CA, Cronbach's Alpha; n, number; Obt int, obtained interval; SD, standard deviation.

*Punctuation $\geq 12$ in the Hospital Anxiety and Depression Scale (HADS) 
Table 3 Distribution of behavioral, psychological and obstetrical variables and their association with depressive symptoms in pregnant women from two public maternity hospitals of reference in the city of Goiânia, Brazil, $2015(n=375)$

\begin{tabular}{|c|c|c|c|c|c|c|}
\hline \multirow[t]{3}{*}{ Characteristics } & \multicolumn{4}{|c|}{ Depressive symptoms ${ }^{* * *}$} & \multirow{2}{*}{\multicolumn{2}{|c|}{ Statistics }} \\
\hline & \multicolumn{2}{|l|}{ Yes } & \multicolumn{2}{|l|}{ No } & & \\
\hline & $\mathrm{n}$ & $\%$ & $n$ & $\%$ & PR $(95 \% \mathrm{Cl})$ & $p$ \\
\hline \multicolumn{7}{|c|}{ Behavioral variable } \\
\hline \multicolumn{7}{|c|}{ Physical activity during pregnancy } \\
\hline No & $53 / 303$ & 17.49 & $250 / 303$ & 82.51 & $3.96(1.28-12.31)$ & $0.006^{*}$ \\
\hline Yes & $3 / 68$ & 4.41 & $65 / 68$ & 95.59 & & \\
\hline \multicolumn{7}{|c|}{ Psychiatric history } \\
\hline \multicolumn{7}{|c|}{ Previous mental problem } \\
\hline Yes & $9 / 24$ & 37.50 & $15 / 24$ & 62.50 & $2.66(1.49-4.73)$ & $0.002^{*}$ \\
\hline No & $49 / 347$ & 14.12 & $298 / 347$ & 85.88 & & \\
\hline \multicolumn{7}{|c|}{ Previous family depression } \\
\hline Yes & $18 / 80$ & 22.50 & $62 / 80$ & 77.50 & $1.68(1.02-2.78)$ & $0.046^{*}$ \\
\hline No & $38 / 284$ & 13.38 & $246 / 284$ & 86.62 & & \\
\hline \multicolumn{7}{|c|}{ Violence variables } \\
\hline \multicolumn{7}{|c|}{ Suffered physical violence } \\
\hline Yes & $4 / 11$ & 36.36 & $7 / 11$ & 63.64 & $2.43(1.07-5.52)$ & $0.075^{* *}$ \\
\hline No & $54 / 363$ & 14.96 & $307 / 361$ & 85.04 & & \\
\hline \multicolumn{7}{|c|}{ Suffered psychological/emotional violence } \\
\hline Yes & $36 / 96$ & 37.50 & $60 / 96$ & 62.50 & $4.74(2.94-7.64)$ & $0.001^{*}$ \\
\hline No & $22 / 278$ & 7.91 & $256 / 278$ & 92.09 & & \\
\hline \multicolumn{7}{|c|}{ Obstetrical variables } \\
\hline \multicolumn{7}{|c|}{ Obstetric complications in the current pregnancy } \\
\hline Yes & $35 / 141$ & 24.82 & $106 / 141$ & 75.18 & $2.53(1.55-4.13)$ & $0.001^{*}$ \\
\hline No & $22 / 224$ & 9.82 & $202 / 224$ & 90.18 & & \\
\hline
\end{tabular}

Abbreviations: $\mathrm{Cl}$, confidence interval; $\mathrm{n}$, number; $\mathrm{PR}$, prevalence ratio.

${ }^{*}$ Chi-square test; ${ }^{* *}$ Fisher's Exact Test; ${ }^{* * *}$ Score $\geq 12$ on the subscale of depression from the Hospital Anxiety and Depression Scale (HADS).

- Table 3 shows that, among the pregnant women who exercised (18.33\%), the majority (62.96\%) performed physical activities two or three times a week. Also, $6.47 \%$ of the women reported "prior mental problems", that is, they had sought a doctor because of mental disorders.

We also observed that $25.67 \%$ of the participants had suffered psychological and emotional violence. The variables "previous mental problem", "performs physical activity", and "obstetric complications during pregnancy" showed a positive association with depressive symptoms. The main diagnoses of this last variable were: supervision of pregnancy risk (20.83\%) and unspecified congenital malformations (2.47\%).

Considering the logistic regression model ( - Table 4 ), the variables with the most significant association were "suffered psychological or emotional violence", which increased in nearly six times the odds of developing depressive symptoms, and "physical activity during the pregnancy". Not exercising during pregnancy raised almost four times the possibilities of this symptomatology.

\section{Discussion}

The prevalence of depressive symptoms among pregnant women attending reference services was of $15.47 \%$. Besides the physical inactivity, which was significantly detrimental to the mental health of the mother, associated to the onset of depressive symptom episodes of psychological violence, previous mental problem, partner absence and the occurrence of obstetric complications in the current pregnancy.

The only psychosocial situation related to depressive symptoms during prenatal care was the condition of being single or separated. A survey conducted in the Brazilian public health system associated gestational depression to stressful events such as the absence of a partner. ${ }^{3,27}$ The vulnerability of women during pregnancy aggravates these factors, especially in developing countries, where there is more socioeconomic diversity and health care services are seldom function properly.

Social support has a beneficial effect on depressive pregnant women. ${ }^{5}$ Therefore, we suggest that preventive 
Table 4 Logistic regression analysis of the events associated with depressive symptoms, according to the violence, behavioral, psychological, social and obstetrical variables, $2015(n=375)$

\begin{tabular}{|l|l|l|l|}
\hline \multirow{2}{*}{ Characteristics } & \multicolumn{2}{l|}{ Statistic } & \multicolumn{2}{l|}{} \\
\cline { 2 - 4 } & OR & $(95 \% \mathrm{Cl})$ & \\
\hline Violence variables & & & 0.001 \\
\hline Suffered psychological/emotional violence & 5.821 & $2.939-11.528$ & 0.997 \\
\hline Suffered physical violence & 0.997 & $0.244-4.084$ & \\
\hline Behavioral variable & & & 0.041 \\
\hline Physical activity during pregnancy & 3.885 & $1.060-14.231$ & \\
\hline Psychological variables & & & 0.074 \\
\hline Previous mental problem & 2.774 & $0.904-8.511$ & 0.897 \\
\hline Previous family depression & 1.055 & $0.473-2.350$ & \\
\hline Obstetrical variable & & & 0.010 \\
\hline Obstetric complications in the current pregnancy & 2.442 & $1.233-4.834$ & \\
\hline Social variables & & & 0.008 \\
\hline Single/Separated & 2.943 & $1.326-6.533$ & 0.297 \\
\hline Years of education & 1.483 & $0.707-3.114$ & \\
\hline
\end{tabular}

Abbreviations: $\mathrm{Cl}$, Confidence Interval; n, number; OR, odds ratio.

interventions ${ }^{28}$ should be made with these pregnant women without a partner, such as developing in them the positive capacity to face hardships. ${ }^{14}$ However, the main option to assistance for these women, the basic health units (BHUs), has infrastructure and professional training problems, which can lead to unable calls. ${ }^{29}$ In short, comprehensive care can help minimize, among other factors, the suffering of the mother/child and the increase in premature and surgical births. $^{7}$

In relation to the adopted instrument, we inferred that, despite the many available tools for the quantification of depressive symptoms (scales, instruments and questionnaires), we opted for the HADS $^{21}$ because of its simplified application, but, above all, because it has been employed in a similar population. ${ }^{3}$

The percentage of depressive symptoms found in this study was lower than in Asia (17.5\%) and Western Europe $(19.5 \%){ }^{7}$ The prevalence of these symptoms in prenatal care in developed countries was greater than in developing countries, including Brazil (ranging between 15\% and 28\%). ${ }^{3,4}$ These differences may be related, among other factors, to the prevalence of cross-sectional studies ${ }^{30}$ and the low representation of samples. ${ }^{3,31}$ It is also worthy $\mathrm{f}$ mention the diversity of assessment tools used ${ }^{3,31}$ and the sociocultural heterogeneity of nations. For example, in predominantly patriarchal societies like in Pakistan, depression can afflict more than half of pregnant women. ${ }^{32}$

Research indicates that prior mental problems can trigger a depressive symptomatology during pregnancy. ${ }^{33}$ This study acknowledges, in multivariate analysis, an indicative of association between previous mental health and depressive symptoms. This finding confirms the need for the multidisciplinary team to have adequate tools to detect this symptomatology during prenatal care.

From this study it also appears that there is no association between physical activity and the emergence of depressive symptoms. This was ratified in the multivariate analysis, which marks an increase of almost four times the odds of manifestation of symptoms. It is important to remember that treating depression during pregnancy is difficult for both the patient and the healthcare team, because antidepressants bring obstetrical and fetal risks. ${ }^{34}$ Based on this, the non-drug treatment would be an important option, in which simple measures like hiking could be taken to minimize the problem.

Several surveys conducted in different countries, such as Norway, indicate an association between physical activity during pregnancy and the lower prevalence of low back and pelvic pain and depression in late pregnancy, which is directly proportional to the amount of weeks of exercise. ${ }^{35}$ These results validate our findings; therefore, within the population who exercised (18.33\%), the majority (62.96\%) was assiduous, and exercised three times a week. The high frequency in physical activities possibly contributed to the non-manifestation of depressive symptoms.

This study found a statistically significant association between psychological or emotional violence and depressive symptoms during prenatal care. Several authors have observed this connection. Psychological violence, although it does not leave visible signs like physical violence, can cause problems that are difficult to treat. It is also noted that any form of violence can harm the health of pregnant women, causing them to feel insecurity, low self-esteem and depression. ${ }^{36}$ These episodes usually occur in contexts in which the women have low schooling and a submissive relationship 
with their partners, which are the result of a historical sociocultural inequality that leads to these relationships of discrimination, subordination and abuse observed nowadays. $^{37}$

There is a growing concern about the effects of stress and depression on the fetal environment. It is well known that the levels of sexual and other hormones, like cortisol, prolactin, thyroxine, are increased during pregnancy. In addition to this increase, complex interactions involving feedback mechanisms between the hypothalamic-pituitary-ovarian axis and the hypothalamic-pituitary-adrenal axis (HPA) have been observed. The HPA axis is especially important, because it involves cortisol, the adrenocorticotropic hormone and the corticotropin releasing hormone, which have their levels altered by both pregnancy and stress. There is the suspicion that high levels of cortisol resulting from stress or pregnancy affect the mood of pregnant women. ${ }^{38}$ This finding corroborates with the findings of this study, in which the variables "suffered psychological/emotional violence" and "obstetric complications during pregnancy", which are considered stressful, had a relationship with the depressive symptoms in the logistic regression analysis.

The main diagnosis that generated "obstetric complications during the pregnancy" was a risk pregnancy monitoring with $20.83 \%$. They are related to risk pregnancy, mainly obstetric and reproductive history, maternal medical condition, drug use and the financial and emotional issues. ${ }^{39}$

A study of gestational depression found a significant association with several pregnancy complications, such as bleeding in the prenatal and placental abruption. It is important to observe that some of these results were significantly associated with mild depression, demonstrating that any degree of depression can have significant influence in the context of obstetric complications. ${ }^{40}$

In the group that participated in this study, it is clear that the lack of a partner, relationship difficulties, and potentially stressful psychological violence may also explain the manifestation of problems during pregnancy, for they cause suffering and uncertainty about its outcome. Thus, the emergence of obstetric complications is multifactorial, and these factors are correlated, culminating in a difficult pregnancy. These problems during pregnancy can be viewed by the women as a punishment, and cause feelings of guilt, enhancing the depressive symptoms.

This study showed many strengths as the pilot of adoption and use of instrument internationally recognized and validated in Brazil. Finally, it is also noteworthy that was made sample calculation and the sample was representative.

On the other hand, the cross-sectional lineation limited interpretations about causality. Cause and effect were observed simultaneously, preventing an analysis of the origin of the depressive symptoms and the direction of these associations. Finally, it was not possible to generalize the findings to the private health sector, although the population studied belongs to two outpatient institutions with large areas of coverage.

Due to the prevalence of depression during pregnancy and the conflicts that can bring to the mother and child, psycho- logical care should be an integral part of obstetrical care. We suggest the implementation of routine instruments to screen for depression during prenatal care, and the referral of severe cases to a psychiatrist.

\section{Acknowledgments}

The study was funded by Coordenação de Aperfeiçoamento de Pessoal de Nível Superior (Capes). There is no conflict of interests.

\section{Referências}

1 Shakeel N, Eberhard-Gran M, Sletner L, et al. A prospective cohort study of depression in pregnancy, prevalence and risk factors in a multi-ethnic population. BMC Pregnancy Childbirth 2015;15:5

2 Wisner KL, Sit DK, McShea MC, et al. Onset timing, thoughts of self-harm, and diagnoses in postpartum women with screenpositive depression findings. JAMA Psychiatry 2013;70(5): 490-498

3 Pereira PK, Lovisi GM. Prevalência da depressão gestacional e fatores associados. Rev Psiquiatr Clín. 2008;35(4):144-153

4 Faisal-Cury A, Menezes PR. Antenatal depression strongly predicts postnatal depression in primary health care. Rev Bras Psiquiatr 2012;34(4):446-450

5 Thiengo DL, Santos JFC, Fonseca DL, Abelha L, Lovisi GM. Depressão durante a gestação: um estudo sobre a associação entre fatores de risco e de apoio social entre gestantes. Cad Saúde Coletiva. 2012;20(4):416-426

6 Van Hyssteen L. Need for wider recognition of antenatal depression. Ther Today. 2008;19:28

7 Yedid Sion M, Harlev A, Weintraub AY, Sergienko R, Sheiner E. Is antenatal depression associated with adverse obstetric and perinatal outcomes? J Matern Fetal Neonatal Med 2016;29(6): 863-867

8 Yusuff AS, Tang L, Binns CW, Lee AH. Antenatal depressive symptoms and breastfeeding: a prospective cohort study. Breastfeed Med 2015;10(6):300-304

9 Campbell JC, Szumlinski KK, Kippin TE. Contribution of early environmental stress to alcoholism vulnerability. Alcohol 2009; 43(7):547-554

10 Vythilingum B, Roos A, Faure SC, Geerts L, Stein DJ. Risk factors for substance use in pregnant women in South Africa. S Afr Med J 2012;102(11 Pt 1):851-854

11 World Health Organization [Internet]. Depression is a common illness and people suffering from depression need support and treatment: WHO marks 20th Anniversary of World Mental Health Day: note for the media 9. Geneva: WHO; 2012 [cited 2016 Apr 20]. Available from: http://www.who.int/mediacentre/news/ notes/2012/mental_health_day_20121009/en/

12 Escribà-Agüir V, Royo-Marqués M, Artazcoz L, Romito P, RuizPérez I. Longitudinal study of depression and health status in pregnant women: incidence, course and predictive factors. Eur Arch Psychiatry Clin Neurosci 2013;263(2):143-151

13 Whiteford HA, Ferrari AJ, Degenhardt L, Feigin V, Vos T. The global burden of mental, neurological and substance use disorders: an analysis from the Global Burden of Disease Study 2010. PLoS ONE 2015;10(2):e0116820

14 Lau Y, Wang Y, Kwong DH, Wang Y. Are different coping styles mitigating perceived stress associated with depressive symptoms among pregnant women? Perspect Psychiatr Care 2016;52(2): 102-112

15 Battle CL, Abrantes AM, Schofield CA, Kraines MA. Physical activity as an intervention for antenatal depression: rationale for developing tailored exercise programs for pregnant women 
with depression. J Midwifery Womens Health 2015;60(5): 479-482

16 Ussher M, Lewis S, Aveyard P, et al. Physical activity for smoking cessation in pregnancy: randomised controlled trial. BMJ 2015; 350:h2145

17 Viellas EF, Gama SG, Carvalho ML, Pinto LW. Factors associated with physical aggression in pregnant women and adverse outcomes for the newborn. J Pediatr (Rio J) 2013;89(1):83-90

18 Hulley SB, Cummings SR, Browner WS, Grady DG, Newman TB. Delineando a pesquisa clínica: uma abordagem epidemiológica. 3a ed. Porto Alegre. Art Med 2008

19 de Empresas de Pesquisa AB. (ABEP) [Internet]. Critério de Classificação Econômica Brasil. 2015 [citado 2015 Out 14]. Disponível em: http://www.abep.org/criterio-brasil

20 Zigmond AS, Snaith RP. The hospital anxiety and depression scale. Acta Psychiatr Scand 1983;67(6):361-370

21 Botega NJ, Pondé MP, Medeiros P, Lima MG, Guerreiro CAM. Validação da escala hospitalar de ansiedade e depressão (HAD) em pacientes epiléticos ambulatoriais. J Bras Psiquiatr 1998; 47(6):285-289

22 Bowling A, Ebrahim S. Handbook of health research methods: investigation, measurement and analysis. Maidenhead: Open University Press; 2005

23 Urbina S. Fundamentos da testagem psicológica. Porto Alegre: Artmed; 2007. Capítulo 4: Fundamentos em fidedignidade; 121-212

24 Nunnally JC. Psychometric theory. 2nd ed. New York: McGrawHill; 1967

25 Coutinho LM, Scazufca M, Menezes PR. Methods for estimating prevalence ratios in cross-sectional studies. Rev Saude Publica 2008;42(6):992-998

26 Browner WS. Publishing and presenting clinical research. 3rd ed. Philadelphia: Lippincott Williams \& Wilkins; 2012

27 Silva RA, Jansen K, Souza LDM, et al. Depression during pregnancy in the Brazilian public health care system. Rev Bras Psiquiatr 2010;32(2):139-144

28 Cankorur VS, Abas M, Berksun O, Stewart R. Social support and the incidence and persistence of depression between antenatal and postnatal examinations in Turkey: a cohort study. BMJ Open 2015; 5(4): e006456

29 Reis LA, Brito FR, Moreira VS, Aguiar ACSA. Atuação do enfermeiro do Programa de Saúde da Família frente ao indivíduo portador de transtorno mental. Ciênc Desenv. 2013;6(2):175-187

30 Choi SK, Park YG, Park IY, Ko HS, Shin JC. Impact of antenatal depression on perinatal outcomes and postpartum depression in Korean women. J Res Med Sci 2014;19(9):807-812
31 Fisher J, Tran T, La BT, Kriitmaa K, Rosenthal D, Tran T. Common perinatal mental disorders in northern Viet Nam: community prevalence and health care use. Bull World Health Organ 2010; 88(10):737-745

32 Waqas A, Raza N, Lodhi HW, Muhammad Z, Jamal M, Rehman A. Psychosocial factors of antenatal anxiety and depression in Pakistan: is social support a mediator? PLoS ONE 2015;10(1): e0116510

33 Kohlhoff J, Hickinbotham R, Knox C, Roach V, Barnett Am B. Antenatal psychosocial assessment and depression screening in a private hospital. Aust N Z J Obstet Gynaecol 2016;56(2): 173-178

34 Chaudron LH. Complex challenges in treating depression during pregnancy. Am J Psychiatry 2013;170(1):12-20

35 Gjestland K, Bø K, Owe KM, Eberhard-Gran M. Do pregnant women follow exercise guidelines? Prevalence data among 3482 women, and prediction of low-back pain, pelvic girdle pain and depression. Br J Sports Med 2013;47(8):515-520

36 Rees SJ, Tol W, Mohammad M, et al. A high-risk group of pregnant women with elevated levels of conflict-related trauma, intimate partner violence, symptoms of depression and other forms of mental distress in post-conflict Timor-Leste. Transl Psychiatry 2016;6:e725

37 Nery IS, Santos AG, Vasconcelos TB. Repercussões da violência intrafamiliar contra mulheres grávidas [Internet]. In: Anais do 17o Encontro Nacional da Rede Feminista Norte e Nordeste de Estudos e Pesquisa sobre a Mulher e Relações de Gênero. 2012 [citado 2015 Fev 12]. Disponível em: http://www.ufpb.br/evento/ lti/ocs/index.php/17redor/17redor/paper/view/310/140

38 Giesbrecht GF, Letourneau N, Campbell T, Kaplan BJ. APrON Study Team. Affective experience in ecologically relevant contexts is dynamic and not progressively attenuated during pregnancy. Arch Women Ment Health 2012;15(6): 481-485

39 Brasil. Ministério da Saúde [Internet]. Portaria n. 1.020, de 29 de maio de 2013. Institui as diretrizes e normas organização da Atenção à Saúde na Gestação de Alto Risco. Casa de Gestantes, Bebê e Puérpera (CGBP) em conformidade com a Rede Cegonha. Brasília (DF): Ministério da Saúde; 2013 [citado 2015 Abr 20]. Disponível em: http://bvsms.saude.gov.br/bvs/saudelegis/gm/ 2013/prt1020_29_05_2013.html

40 Schwartz L, Bowen A, Muhajarine N. The effects of episodic versus continuous and major versus mild depression and anxiety symptoms on pregnancy and labour complications. Arch Depress Anxiety. 2015;1(1):10-18 